\title{
Development of Picture Matching Material Using RFID for Challenged People
}

\author{
Koki SHIBASATO ${ }^{\mathrm{a},}$, Akihiro HORIGUCHI ${ }^{\mathrm{b}}$, Hirofumi OHTSUKA ${ }^{\mathrm{a}}$, Yasuyuki SHIMADA ${ }^{\mathrm{c}}$ \\ ${ }^{a}$ Dept. of Control and Information Systems Engineering, National Institute of Technology, Kumamoto College, \\ 2659-2 Suya, Koshi, Kumamoto, Japan \\ ${ }^{\mathrm{b}}$ Dept. of Electronic and Information Systems Engineering, National Institute of Technology, Kumamoto College, \\ 2659-2 Suya, Koshi, Kumamoto, Japan \\ ${ }^{\mathrm{c}}$ Global Leadership Development Center, National Institute of Technology, Kumamoto College, \\ 2659-2 Suya, Koshi, Kumamoto, Japan
}

*Corresponding Author: shiba@kumamoto-nct.ac.jp

\begin{abstract}
The Japanese government conducted measures for persons with disabilities in 2013 and they reported that about 2.2 million of challenged children aged 17 or younger live in Japan. It is obvious that the fine-tuned education should be provided for the degree of each disability for children with disabilities to become independent, and participate in a society. Therefore Japanese government set up special needs education school and special needs classes in elementary school and junior high school. And many special trained teachers are assigned to the special needs education schools and the special needs classes. One of the special needs education schools managed by Japanese Government is near our college, named Kuroishibaru special needs education school. Our college has kept good relationship with Kuroishibaru special needs education school since 2013 and been collaborating with each other. More than one hundred students with severe disabilities study in the school and teachers have to be with the students at any time because most of the children cannot move their hands or legs voluntarily. The teachers are extremely sensitive to children's facial expression so that teachers can guess what/how the children think/feel, meanwhile the children cannot communicate with others outside of the school.

In this paper we propose a teaching material "picture matching toy with RFID”. By using three-dimensional objects such as stuffed animals used for the everyday activities, it is expected that introduction of learning, sustaining interest and arranging according to children can
\end{abstract}

become easy. In particular, the teaching materials has a characteristic that the learning history can be visualized. Teachers recognize a learning effect of the children and can apply the teaching material adequately. Therefore, it is expected that teachers will foster the ability of children with disabilities to participate in a society.

Keywords: Assistive Technology, Special Needs Education School, Picture Matching Material

\section{Introduction}

According to the annual report on government measures for persons with disabilities conducted in 2013, the number of persons with physical and/or intellectual disabilities is about 4,210,000. The number of persons with disabilities aged 17 or younger is about 223,000. Those children cannot communicate with others without somebody's help because of severe physical disabilities and they are wholeheartedly keen to become a member of a society and crave a device/application to communicate with other people $\mathrm{e}^{(1)}$.

It is obvious that the fine-tuned education should be provided for the degree of each disability for children with disabilities to become independent, and participate in a society. Therefore Japanese government set up special needs education school and special needs classes in elementary school and junior high school. And many special trained teachers are assigned to the special needs education schools and the special needs classes.

Indeed, there are many models of picture matching 
material produced in Japan, however, quite small number of products are designed for the challenged children because difficulties of the children are unique and each assistive device should be designed individually. Therefore it's not easy to produce common-use devices or applications, and it's not easy for company to gain a profit from such special devices/applications. Finally, few types of assistive product are available even though a lot of challenged children desire such assistive device and application to be produced.

One of the special needs education schools managed by Japanese Government is near our college, named Kuroishibaru special needs education school ${ }^{(2)}$. Our college has kept good relationship with Kuroishibaru special needs education school since 2013 and been collaborating with each other. More than one hundred students with severe disabilities study in the school and teachers have to be with the students at any time because most of the children cannot move their hands or legs voluntarily. Some of them cannot move even fingers or shake their head.

In this paper we propose a picture matching toy with RFID as a teaching material. It is possible to use threedimensional objects such as stuffed animals used for the everyday activities, it is expected that introduction of learning, sustaining interest and arranging according to children can become easy. This application was developed by an inclusive design method. This method is involving an enduser from first phase. Therefore, teacher and student's opinion was adopted. Teaching material was developed to support for independence of challenged people.

\section{Learning in Special Needs Education School}

\subsection{Picture Matching}

Students who belong support school need to learn basic things repeatedly. Picture matching is the one of the teaching material for them. It uses a pair card. After teacher present the question, student chooses same card among the choices. It is used for independence activities. It mainly expects the following effects ${ }^{(3)}$.

$\checkmark$ determining the eye fixation point of a student

$\checkmark$ learning letters

$\checkmark \quad$ understanding about number

$\checkmark$ recognizing that an object has a name

$\checkmark \quad$ confirmation the object's name once learned

$\checkmark$ showing the feeling of a student who cannot speak

$\checkmark$ finger exercise
An example of handmade teaching material is shown in figure 1. The left photo shows picture matching material and the right one shows form fitter. When students play picture matching material, they choose the same cad. Similarly, in the case of form fitter, students choose the object same shape and put it into a hollow. Also, the basic flowchart of learning that teacher and student do together using matching material is shown in figure 2 .

\subsection{Categorizing}

When student uses the picture matching material, student learns about one-to-one correspondence. A categorizing is defined as not only finding same object but also recognizing same group. It is shown in figure 3 . There

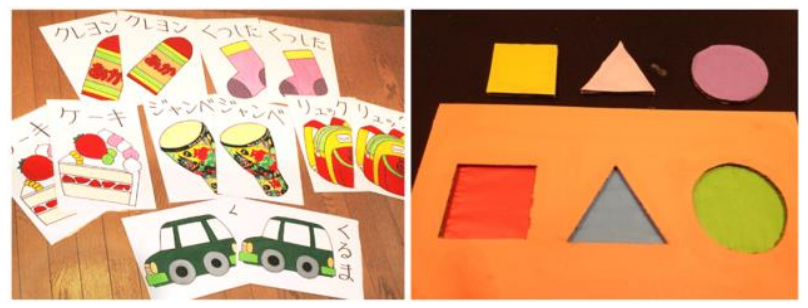

Fig. 1. Handmade teaching material ${ }^{(4)(5)}$

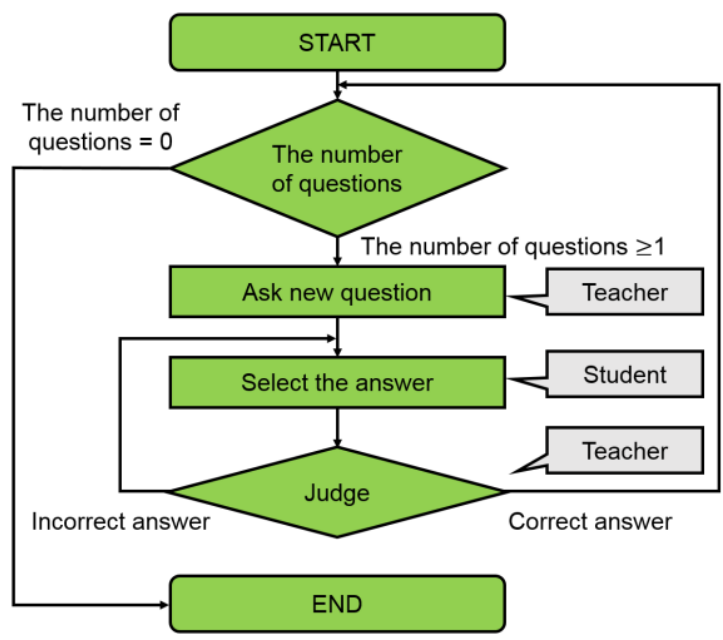

Fig. 2. Flowchart of learning using matching material

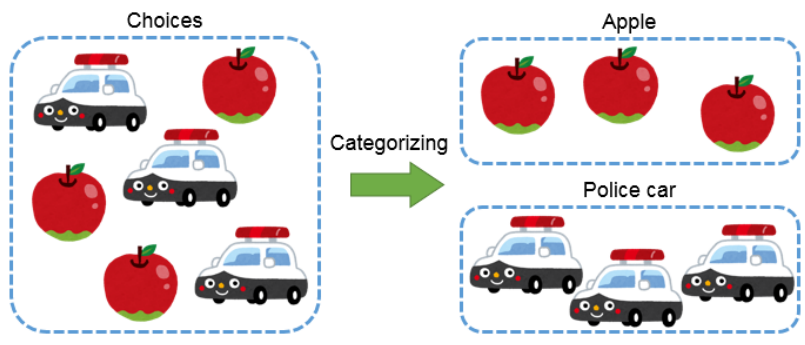

Fig. 3. Categorizing 
are many choices belong to different categories. Students have to choose same category among choices. The aim of this learning is understanding a general inclusive concept. Normal picture matching has one answer for one question. However, categorizing has plural answer for one question. Therefore, the categorizing is more difficult than picture matching.

\subsection{Recognizing Relationship between an Object and Letters}

It is more difficult than categorizing to recognize relationship between an object and letters because student has to recognize the general inclusive concept that an object is able to be described by some letters. The aim of this study is to make student understood the name. Also, it assumes following learning phases. At first phase, student recognize that an object has its name and the name can be expressed by letters. In this phase, the correct letters and the order are not be cared. In next phase, a student recognizes its correct letters and order. The Japanese language has many homonym. In third phase, a student construes a homonym which has same letters and order and has different meaning. It is identified from context or intonation. For example, a pronunciation "ha-shi" in Japanese means chopsticks, a bridge and an edge of an object. The intonation is different, however, Japanese hiragana letters are exactly equivalent. Table 1 and Figure 4 show the each phase.

\section{Picture Matching Material Using RFID}

\subsection{Radio frequency identifier}

RFID is an acronym for radio frequency identification, which is a wireless communication technology that is used to uniquely identify tagged objects ${ }^{(6)}$. Tags are attached to objects to be identified in an RFID. A tag is typically composed of an antenna or coupling element, and integrated circuitry. Often tags carry no on-board power source and

Table 1. Recognizing relationship between an object and letters

\begin{tabular}{|c|c|}
\hline Phase & Learning level \\
\hline $1^{\text {st }}$ phase & $\begin{array}{l}\text { An object has its name and the name can be } \\
\text { expressed by letters. }\end{array}$ \\
\hline $2^{\text {nd }}$ phase & $\begin{array}{l}\text { The word is constructed by correct letters and } \\
\text { has order. }\end{array}$ \\
\hline $3^{\text {rd }}$ phase & $\begin{array}{l}\text { The understanding that word is different } \\
\text { mean in spite of same sound. }\end{array}$ \\
\hline
\end{tabular}
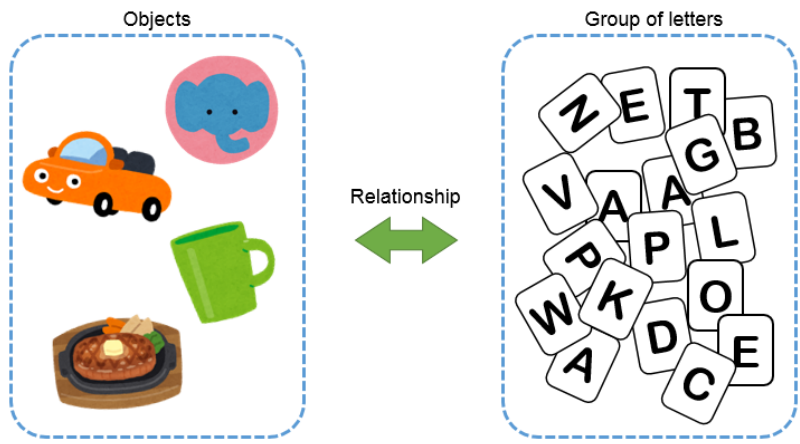

(1) First phase

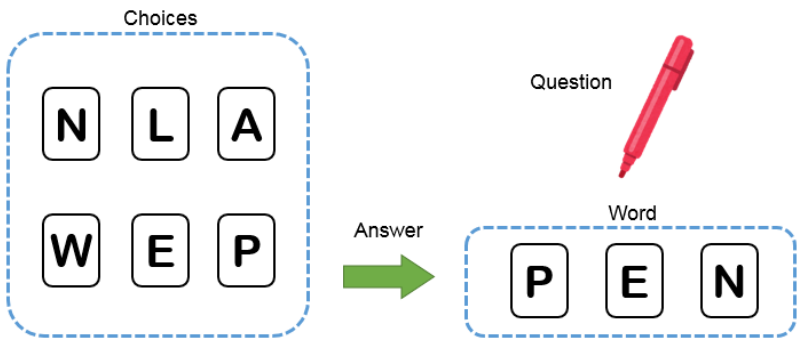

(2) Second phase

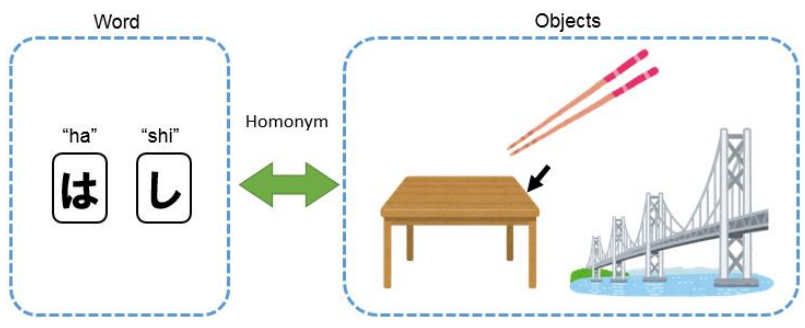

(3) Third phase

Fig. 4. Recognizing relationship between an objects and letters (first phase, second phase, third phase)

must passively harvest all energy from an RF signal. Figure 5 shows one of the RFID system: FeLiCa reader and its tag.

\subsection{Development with inclusive design method}

In recent years, the effective utilization of ICT has attracted attention in special needs education. Especially, applications on tablet computer are developed for challenged
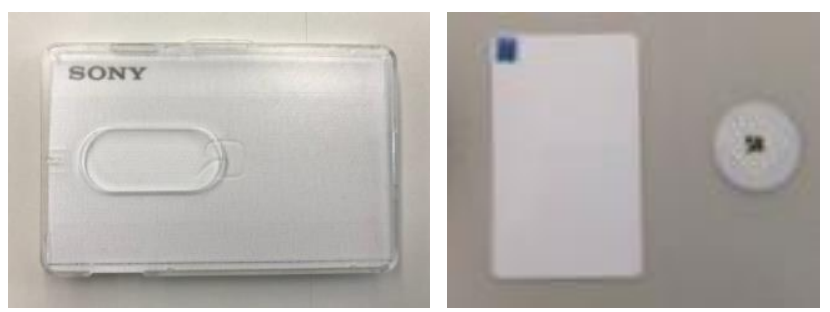

Fig. 5. RFID reader and tag 
people and it is expected to be practical means. However, most of the children cannot move their hands voluntarily, it is difficult to touch the panel and control the application. It is suitable for such children to use physical objects with hand-feeling that do not need to fine work.

Therefore, the teaching material has been developed with teachers and students from plan and design phase. The British Standards Institute defines inclusive design as "The design of mainstream products and/or services that are accessible to, and usable by, as many people as reasonably possible on a global basis, in a wide variety of situations, and to the greatest extent possible without the need for special adaptation or specialized design."(7) The inclusive design process stands out when it comes to the choice of which users to involve. In opposite to a regular approach, the inclusive design method requires that the included users have characteristics that will demand more from the solution than an average customer. The picture matching material using RFID has been developed since 2013, and has been continued to discuss with teachers in Kuroishibaru special needs education school. Figure 6 shows discussion with teachers about prototype. In usual picture matching material, only teacher tell the student correct/incorrect cheerfully to encourage student. The proposed material using RFID can play music and show picture when student chooses answer. Therefore, children are encouraged by multi modal way: a visual sense, an auditory sense and a tactile sense. If the sound is favorite one for them and they are looking forward to hear, it is expected to be maintained their interest to study. Also, RFID tag can be attached to stuffed animals and daily necessaries they use, all their personal belonging become a matching material. As a result, it is easy to introduce learning

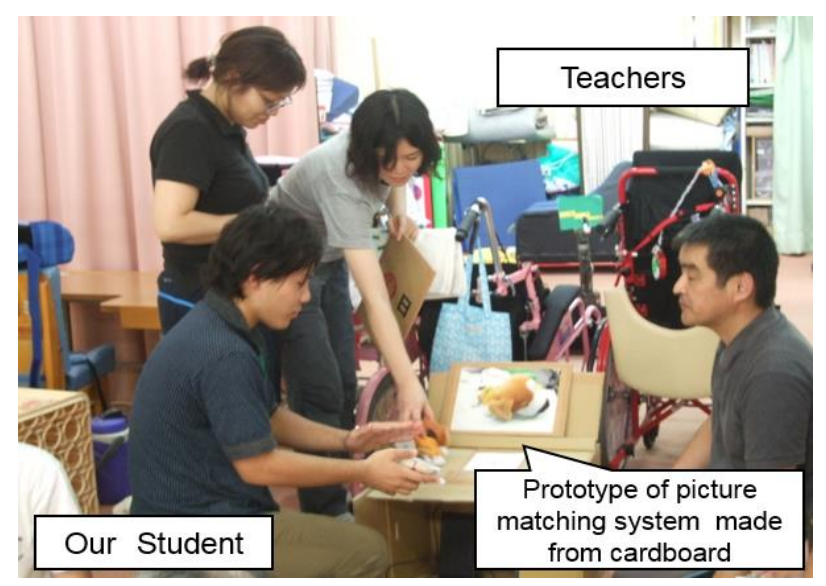

Fig. 6. Discussion about prototype design with teachers in Kuroishibaru special needs education school contents for children and it is better than existing item in terms of self-recognition. Also, it can make contrive easy for teachers depending on children's individuality.

\section{Implementation and Evaluation}

\subsection{Basic specifications}

The proposed picture matching material is composed of RFID reader, tags, cards/stuffed toy and note/tablet PC. RFID tags whose information have been read in advance are putted on cards/stuffed toy. Additionally, a corresponding table is prepared that specifies the behavior of teaching material when children answer correctly/incorrectly. The proposed picture matching material using RFID has five main function and several sub functions shown as follows.

1. Identification objects using RFID

2. Question and answer

3. Basic action to children and teacher
(a) music playing
(b) image showing
(c) animation playback

4. Management of the teaching material
(a) control students' information
(b) setting up RFID tag information
(c) defining correct/incorrect actions

5. Visualizing and feedback

(a) saving learning history automatically

(b) display learning history graphically

RFID tag is a microchip attached to an antenna that is packaged in a way that it can be applied to an object. The tag picks up signals from and sends signals to a reader. The tag contains a unique serial number. Before attaching RFID tag to the objects, the serial number is recorded on the table. Therefore, when the objects with RFID tag is putted on the RFID reader, the program on $\mathrm{PC}$ refers the table and identifies what it is. At first, the teacher shows one object. Next, the child selects the same one from the choices. Since an action in correct/incorrect case has been defined on the corresponding table, it plays music, shows picture and plays back movie after judging the answer depend on the table. If the network is available, the table is controlled on database server. In other case, the program refers the local table on the client PC. When the teaching is finished, the learning history is stored in database. Teachers in special needs education school are able to know learning activities of students and result of analysis. Currently, the server has been built, and 


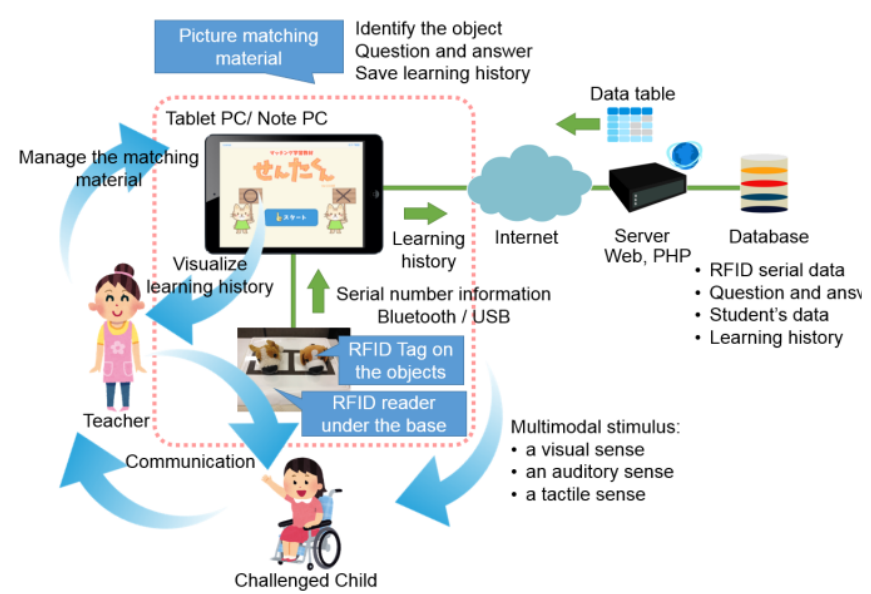

Fig. 7. Data flow from client device to database

the system of connecting between the teaching material and database using PHP and MySQL is implemented. The data flow of the connection from client device to database is shown in figure 7.

\subsection{Trial results}

The students have physically and mentally challenged. Therefore, each teacher is assigned exactly one student. At first, a prototype application was developed on Windows PC. The RFID reader is connect to PC using USB cable and the learning history is stored on the local PC. Through 3 months trial use in special needs education school, the proposed teaching material was evaluated and compared with existing one by teachers and got helpful comments. The result is shown Table 2.

Dramatic impact: our proposed picture matching material was highly appreciated by teachers than existing one because it has a function of playing the music and the music can be changed according to objects. When children use the proposed picture matching material, they can use not only a visual sense and a tactile sense but also an auditory sense. The school teacher said "The child got interested in the proposed teaching material with a twinkle in her eyes more than an existing one, when this teaching material played a favorite music."

Table 2. Trial results

\begin{tabular}{lcccc}
\hline Teaching material & Impact & Preparation & Record & Management \\
\hline $\begin{array}{l}\text { Proposed method } \\
\text { with RFID }\end{array}$ & Excellent & Average & Good & Good \\
$\begin{array}{l}\text { Usual handmade } \\
\text { picture matching }\end{array}$ & Average & Good & Average & Excellent \\
$\begin{array}{l}\text { Usual handmade } \\
\text { form fitter }\end{array}$ & Good & Average & Average & Excellent \\
\hline
\end{tabular}

Preparation: This item is evaluated with regard to labor of preparation. The proposed picture matching material could not get high evaluation compared with existing one because it needs setting of the RFID tag table in advance. Also, the form fitter got poor evaluation since it requires time and effort to make objects by hand.

Record of learning result: This item is evaluated with regard to management of learning history. The proposed picture matching material can record child's learning history in PC automatically. However, existing teaching material has to record it by handwriting after making a mental note of the result. It is difficult to record while learning. Therefore, picture matching using RFID got higher evaluation than existing teaching material.

Management: This item is evaluated with regard to management of a teaching material. An existing teaching material does not easily fail because it does not use electronic component. However, the proposed one requires PC treated with care. Therefore, it did not get high evaluation.

\subsection{Word learning}

The prototype teaching material using RFID copes with only a picture matching. As a result of teacher's comments, the proposed teaching material was improved and an added new functions that deals with first and second phases learning in Table 1. The new teaching material was applied to a same child. The child gave a correct answer roughly in the picture matching questions. Therefore, the child advanced to next phase in order to expand self-reliance activities.

This section describes the second phase: recognizing that an object has a name. The teaching material was applied for student and the child learned with regard to four words: "ma-me", "ma-ma", "ni-ku", and student's name. The words are familiar sound for the child because all the words are used usually to indicate following. "Ma-me" means the nickname of homeroom teacher and "ma-ma" means mother. Also, "ni-ku" means meat in Japanese and the word indicates "meal" for the child. These 3 words are composed of 2 letters and the child's name is composed of 3 letters in Japanese.

The child cannot hold an objects by hand voluntary or speak anything. And also, it is difficult for the child to keep its posture, the child uses a sitting position holding wheelchair in class. However, the child actually can gaze at what it is interested in. Therefore, only facial expression can be a channel to communicate with others. When the student answers by its facial expression, the teacher supports for the answer and sets the card on the pedestal. When teacher sets 


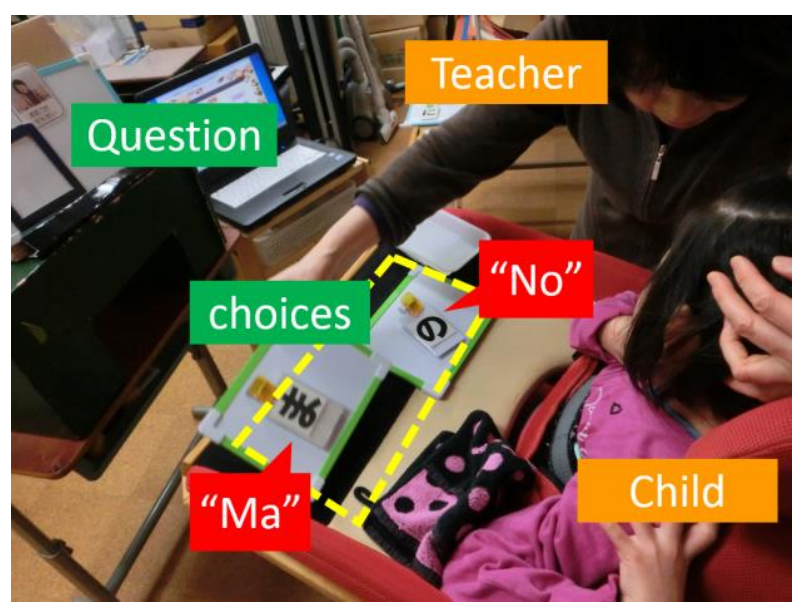

Fig. 8. The child during word learning

the card, the characteristic sound is played as feedback to the student. Figure 8 shows a teaching scene.

It was difficult for the child to answer its name of three letters. Here, only the three words composed of two letters is used to analyze. Student ID information, date, learning time, question type, result of answer, answer time, number of trials and so on were recorded automatically when the child used the teaching material with RFID. The words the child tried to learn are composed of two letters in Japanese. In this learning, the prototype of word learning material was applied, the learning history of the child was recorded on the local PC. Therefore, the learning history was analyzed off-line. Multi regression analysis is applied to the first letter, the second letter and the total. Figure 9 shows answer time for one question. Multi regression analysis is adopted to organize data and find out a relationship between each factors. It is also used to predict the value of a variable based on the value of two or more other variables. The variable to be predict is called the dependent variable. In this study, it is considered that the factor which influence the percentage of correct

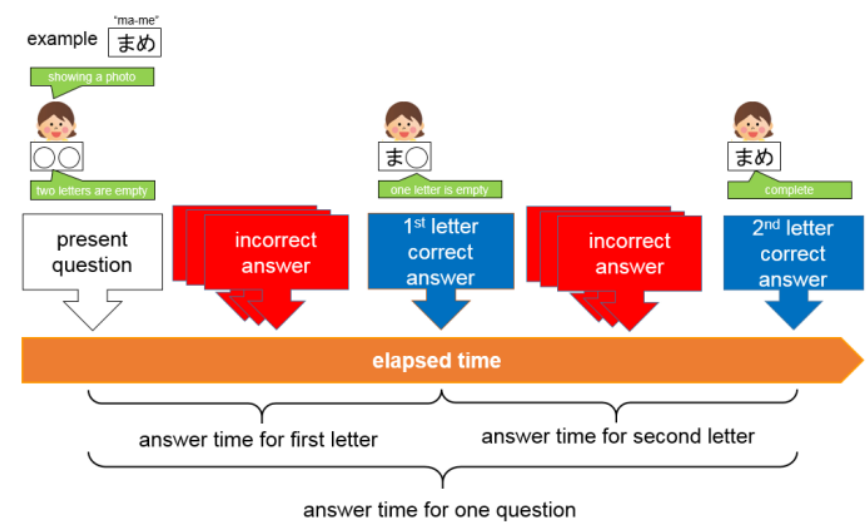

average answer time = answer time for one letter / the number of the answers (incorrect answer is included)

Fig. 9. Answer time for one question

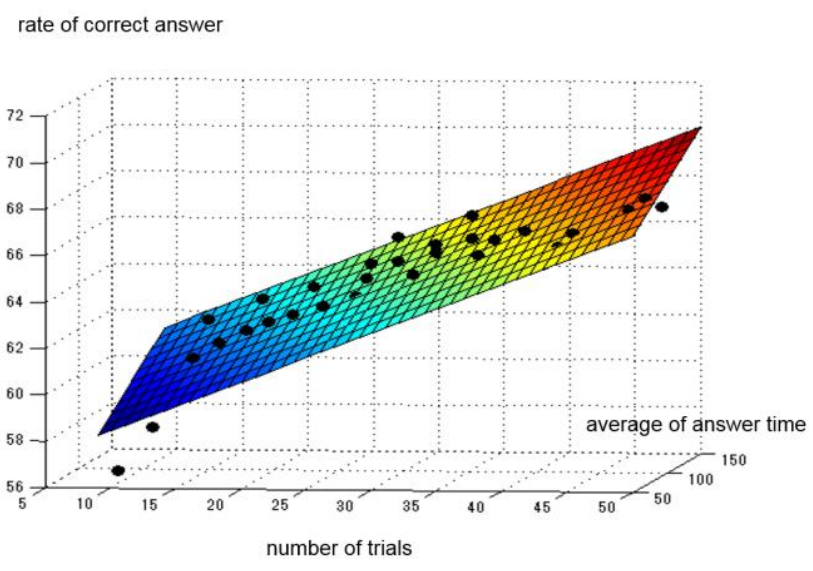

Fig. 10. The percentage of correct answers

answers plays important role of child's learning. Therefore the dependent variable is taken as percentage of correct answers. The analysis result is shown in figure 10. The black dots shows the measured value and the colored plane shows a linear relationship derived by multi regression analysis. This relation shows that the correct rate almost nothing to do with average of the answer time. That means the answer time almost does not become short even if the child continues the study. However, the correct rate increases as the number of trial increases. That is to say, study using the matching material is effective for the child to recognize letter. This result become the motivation for the teacher to study words using the teaching material.

Moreover, an interesting result is obtained by applying multiple regression analysis to each letter. With regard to a first letter, it has as same tendency shown in figure 10: the rate of correct answer increase proportion to the number of trial. However, with regard to the second letter, the relationship between the rate of correct answer and the number of trial almost does not have a correlation and the measurement results have variation. The authors discussed with teachers in Kuroishibaru special needs education school and proposed a hypothesis to explain this result. The child recognizes that each Japanese letter's shape is different and the letter relates to the shown photos. However, the child does not have a concept that a word is consist of two or more letters and the word suggests the shown photo image. Only one letter is associated to the photo.

\section{Conclusion}

In this paper, the picture matching material using RFID for challenged people was proposed. The teaching material has been developed with teachers and students from plan and 
design phase. It can play music, show picture and play movies when student chooses correct/incorrect answer. Therefore, children are encouraged by multi modal way: a visual sense, an auditory sense and a tactile sense. Also, RFID tag can be attached to stuffed animals and daily necessaries they use, all their personal belonging become a matching material. As a result, it was highly appreciated by teachers because it is better than existing item in terms of impact and self-recognition and so on. Moreover, the proposed teaching material was extended to word learning. The teaching material can record children's learning history in PC automatically. Applying multi regression analysis to the result of word learning for the challenged child, it figured out that the rate of correct answer increases proportionally as the number of trial increases. This result encourages the teacher to use the proposed matching material to the student. Simultaneously, it revealed that the child is not good at recognizing the second letter. It is expected that the child recognizes the concept that one word consists of some letters by continuing study with the teaching material and consequently the independence of challenged child is going to be enhanced.

\section{Acknowledgment}

This work was supported by JSPS KAKENHI Grant Number JP15K04583.

Furthermore, this work was supported by the TriInstitutional Collaborative/Cooperative Educational Reform Project with the Nagaoka University of Technology (NUT), Toyohashi University of Technology (TUT) and National Institute of Technology (KOSEN) in Japan.

\section{References}

(1) "The number of challenged people" http://www8.cao.go.jp/shougai/whitepaper/h25hakush o/gaiyou/h1_01.html

(2) "About Kuroishibaru special needs education school" http://sh.higo.ed.jp/kuroishi/gaiyou/

(3) "Effect of a picture matching toy" http://kyozaisupport.com/match00.htm

(4) "Picture matching toy" http://popke.web.fc2.com/pr02.html

(5) "Handmade form fitter" http://funlearn.seesaa.net/article/303883006.html

(6) Klaus Finkenzeller: "RFID Handbook: Fundamentals and Applications in Contactless Smart Cards, Radio
Frequency Identification and Near-Field Communication”, John Wiley \& Sons, 2010

(7) Standards British: "BS 7000-6 2005 Design Management Systems: Managing Inclusive Design Guide”, BSi Standards, 2005 